\title{
Stage II Ureter Cancer AJCC v7
}

National Cancer Institute

\section{Source}

National Cancer Institute. Stage II Ureter Cancer AJCC v7. NCI Thesaurus. Code C6151.

Stage II includes: T2, NO, M0. T2: Tumor invades the muscularis. N0: No regional lymph node metastasis. M0: No distant metastasis. (AJCC 7th ed.) 